\title{
THE INFLUENCE OF PLATINUM ON THE STRUCTURE AND PHOTOCATALYTIC PERFORMANCE OF HYDROGEN TITANATE NANOTUBES
}

\author{
HU XIAO-JING ZHU BAO-LIN* DONG JIAN-XUN ZHAO WEI-LING WANG SHU-RONG \\ ZHANG SHOU-MIN HUANG WEI-PING
}

\author{
(TKL of Metal- and Molecule-Based Material Chemistry and Key Laboratory of Advanced Energy MaterialsChemistry (MOE), \\ Department of Chemistry, Nankai University, Tianjin 300071, China)
}

(Received: June 15, 2011 - Accepted: December 13, 2011)

\begin{abstract}
Via photoreductive deposition process, platinum-modified $\mathrm{TiO}_{2}$ photocatalysts $\left(\mathrm{Pt} / \mathrm{TiO}_{2}\right)$ with various $\mathrm{Pt}$ contents are prepared by using $\mathrm{H}_{2} \mathrm{PtCl} \mathrm{l}_{6}$ and hydrogen titanate nanotubes as precursors. The structures and photocatalytic performances of $\mathrm{Pt} / \mathrm{TiO}_{2}$ obtained are characterized. The experimental results indicate that platinum has obvious influence on the structure and photocatalytic performances of the hydrogen titanate nanotubes. The tubular structures of some nanotubes are destroyed during the photoreductive deposition process. It is possible that the hydrogen coming from splitting water over formed $\mathrm{Pt} / \mathrm{TiO}_{2}$ results in the breach of nanotubes. The existence of platinum can enhance the photocatalytic performance of titanate nanotubes, and the photocatalytic activity arrives at the highest when the Pt content is 1.5 wt.\%.
\end{abstract}

Keywords: hydrogen titanate nanotubes; platinum; photoreductive deposition; tubular structure; photocatalytic performance

As a common semiconductor and photocatalyst, $\mathrm{TiO}_{2}$ has been intensively investigated because of its good catalytic activity, non-toxicity, stability and low cost ${ }^{[1-3]}$. Due to quick recombination of photo-generated charges, the photocatalytic efficiency of pure $\mathrm{TiO}_{2}$ is not high enough ${ }^{[4,5]}$, which limits its practical application greatly. In the field of improving photocatalytic performance and efficiency of $\mathrm{TiO}_{2}$, many works on $\mathrm{TiO}_{2}$ modified with noble metal, metal sulfide, various dopants, etc have been reported ${ }^{[5-12]}$. It has been proved that photocatalytic performance of $\mathrm{TiO}_{2}$ modified with noble metals is better than that of primary $\mathrm{TiO}_{2}$. Many references related to the modification of $\mathrm{TiO}_{2}$ with platinum have been reported. Shi has reported Pt-doped $\mathrm{TiO}_{2}$ fiber catalyst with different Pt contents by photoreductive deposition method ${ }^{[13]}$. Kim has reported titania hollow spheres coated with platinum ${ }^{[14]}$. Siemon and Bahnemann have reported heterogeneous photocatalytic reaction comparing $\mathrm{TiO}_{2}$ and $\mathrm{Pt} / \mathrm{TiO}_{2}{ }^{[15]}$. In most of the reported cases, more active photocatalysts can be prepared via the photoreductive deposition or photodeposition [16]. Compared with photocatalysts with common forms, nanotubes that have larger specific surface area can contact effectively with substrates in the gas or liquid phase, and show better performance. $\mathrm{TiO}_{2}$ nanotubes have not only high specific surface area, but also high sedimentation rate, which makes $\mathrm{TiO}_{2}$ nanotubes more suitable to be utilized as catalyst for the heterogeneous photocatalytic reactions ${ }^{[8,17]}$. To obtain tubular $\mathrm{TiO}_{2}$, a number of synthetic methods, such as electrochemical anodic oxidation of metal titanium foil ${ }^{[18,19]}$, template-assisted synthesis ${ }^{[20]}$, and sol-gel method ${ }^{[21]}$, have been developed, and $\mathrm{TiO}_{2}$ nanotubes with different diameters were fabricated. In 1998, Kasuga et al. developed a hydrothermal method to turn $\mathrm{TiO}_{2}$ powders into tubular structure ${ }^{[22]}$. The obtained nanotubes have uniform diameter of around $10 \mathrm{~nm}$ and high surface area. Compared with other fabrication process, this synthesis process is a cheap one-step reaction, and requires neither expensive apparatus nor special chemicals, which facilitate the scale-up production in low-cost and high-reduplicative. Since then, the characterization and modification of such kind of nanotubes are expansively reported ${ }^{[9,23,24]}$. However, this kind of hydrogen titanate nanotubes are brittle and can be destroyed easily ${ }^{[25]}$. In our previous investigation, we observed that the hydrogen titanate nanotubes can be destroyed after calcinations process at $150^{\circ} \mathrm{C}$ in $\mathrm{H}_{2}$ or during the fabrication process under UV irradiation ${ }^{[6,26]}$, and sol treatment have been used to improve the stability of this kind of titanate nanotubes ${ }^{[9,27]}$. However, the structure transformation of this kind of nanotubes under UV irradiation has not been further investigated. In this paper, platinum-modified $\mathrm{TiO}_{2}$ catalysts with various platinum contents are prepared via photoreductive deposition process. The influence of Pt content on the structure and photocatalytic activity of the nanotube support is also investigated.

\section{EXPERIMENTAL}

\section{Preparation of samples}

All of the chemicals are analytical grade and used without further purification. $\mathrm{TiO}_{2}$ powder is pure anatase crystal. Its specific surface area and particle size are $10 \mathrm{~m}^{2} / \mathrm{g}$ and $100 \mathrm{~nm}$, respectively. Water is of $\sim 18 \mathrm{M} \Omega \cdot \mathrm{cm}$ resistivity.

Titanate nanotubes are synthesized according to the reported procedure ${ }^{[22,26]}$. In a typical synthesis, $1.5 \mathrm{~g}$ raw $\mathrm{TiO}_{2}$ powder is dispersed in $80 \mathrm{~mL} \mathrm{NaOH}$ aqueous solution $(10 \mathrm{M})$ and charged into a $100 \mathrm{~mL}$ Teflon-lined autoclave. The autoclave is heated in an oil bath at $150{ }^{\circ} \mathrm{C}$ for $12 \mathrm{~h}$. Prepared sample is washed with $0.1 \mathrm{M} \mathrm{HCl}$ solution and water, respectively. White powder is obtained after they are dried at $80^{\circ} \mathrm{C}$ in air. Multilayer nanotubes of high quality can be observed with TEM. The preparation process of Pt-modified $\mathrm{TiO}_{2}$ catalyst (marked as $\mathrm{Pt} / \mathrm{TiO}_{2}$ ) is described as follows. The obtained nanotubes are first dispersed in an ethanol solution (1g titanate nanotubes/50 $\mathrm{mL} \mathrm{H}_{2} \mathrm{O}+50 \mathrm{~mL}$ ethanol), and then appropriate $\mathrm{H}_{2} \mathrm{PtCl}_{6}$ solution $(0.9326 \mathrm{mg} /$ $\mathrm{mL}$ ) is added. After stirring for $0.5 \mathrm{~h}$, the suspension is irradiated for $3 \mathrm{~h}$ with a $300 \mathrm{~W}$ High-Pressure Mercury Lamp at a distance of $10 \mathrm{~cm}$ under stirring at room temperature. The obtained $\mathrm{Pt} / \mathrm{TiO}_{2}$ are washed with water to remove $\mathrm{Cl}^{-}$ ions and dried at $80^{\circ} \mathrm{C}$ in air. The contents of platinum, which are calculated by the amount of $\mathrm{H}_{2} \mathrm{PtCl}_{6}$ added, are $0.5 \mathrm{wt} . \%, 1.0 \mathrm{wt} . \%, 1.5 \mathrm{wt} . \%, 2.0 \mathrm{wt} . \%$ and $2.5 \mathrm{wt} . \%$, respectively. The color of samples changes from weak yellow to grey with the increase of platinum contents.

Characterization of samples

The powder X-ray diffraction (XRD) experiments are carried out at room temperature using a Rigaku D/Max-2500 X-ray diffractometer $(\mathrm{CuK} \alpha$ $\lambda=0.154 \mathrm{~nm}$ ) to identify crystal phase of the products. The diffraction peaks of samples are compared with those reported in the JCPDS Data File. TEM images are obtained with a Philips T20ST transmission electron microscopy working at $200 \mathrm{kV}$. UV-visible absorption spectra of the samples are obtained with a JASO V-570 spectrometer. The chemical states of Pt, Ti and $\mathrm{O}$ are investigated by X-ray photoelectron spectroscopy (XPS) using an Al X-ray source (Al $\mathrm{K \alpha}-150 \mathrm{~W}$, Kratos Axis Ultra DLD).

Test of photocatalytic performance

The photocatalytic performances of the samples prepared are evaluated by the degradation rates of methyl orange in water under UV-vis light irradiation. The photocatalyst $(50 \mathrm{mg})$ is dispersed in $100 \mathrm{~mL}$ of methyl orange solution $(13 \mathrm{mg} / \mathrm{L})$. Then the system is irradiated with a $300 \mathrm{~W}$ high-pressure mercury lamp at a distance of $10 \mathrm{~cm}$ and ambient temperature. The concentration of methyl orange solution is monitored by measuring the absorbency of solution at $463.5 \mathrm{~nm}$ using a TU-1901 spectrometer. The results are corrected for the decomposition of the methyl orange in the absence of catalysts and its adhering to the catalyst.

\section{RESULTS AND DISCUSSION}

It is well known that when $\mathrm{TiO}_{2}$ are photoexcited by UV light of HighPressure Mercury Lamp, photogenerated holes $\left(\mathrm{h}^{+}\right)$and electrons $\left(\mathrm{e}^{-}\right)$come into being. The electrons in valence bands can be captured by $\left[\mathrm{PtCl}_{6}\right]^{2-}$ ions that adhere to the nanotubes, and the $\left[\mathrm{PtCl}_{6}\right]^{2-}$ ions are reduced into metal Pt, forming $\mathrm{Pt} / \mathrm{TiO}_{2}$, as a result. The processes can be described as follows: 
(1) $\mathrm{TiO}_{2}+\mathrm{hv} \rightarrow \mathrm{TiO}_{2}+\mathrm{e}^{-}+\mathrm{h}^{+}$; (2) $\left[\mathrm{PtCl}_{6}\right]^{2-}+4 \mathrm{e}^{-} \rightarrow \mathrm{Pt}^{0}+6 \mathrm{Cl}^{-}$.

In order to get detail microstructures of samples, TEM observations are carried out and obvious difference can be seen between the pure titanate nanotubes and $\mathrm{Pt} / \mathrm{TiO}_{2}$. Fig. 1 shows the TEM and HR-TEM images of the sample with $1 \mathrm{wt} . \%$ platinum. It can be seen clearly that the tubular structure of some nanotubes has changed greatly after the irradiation process. Though some nanotubes still keep their tubular structure (Fig. 1A) the length of the most of nanotubes becomes relatively shorter, and some particles appear, which adhere to linear bundles of nanotubes. At high magnification (Fig. 1B), fringes periodicity of the sample is measured as $0.35 \mathrm{~nm}$, which is consistent well with the lattice spacing between $\{101\}$ planes of anatase $\mathrm{TiO}_{2}$. It can be concluded that the tubular structure of most nanotubes is broken during the irradiation process.
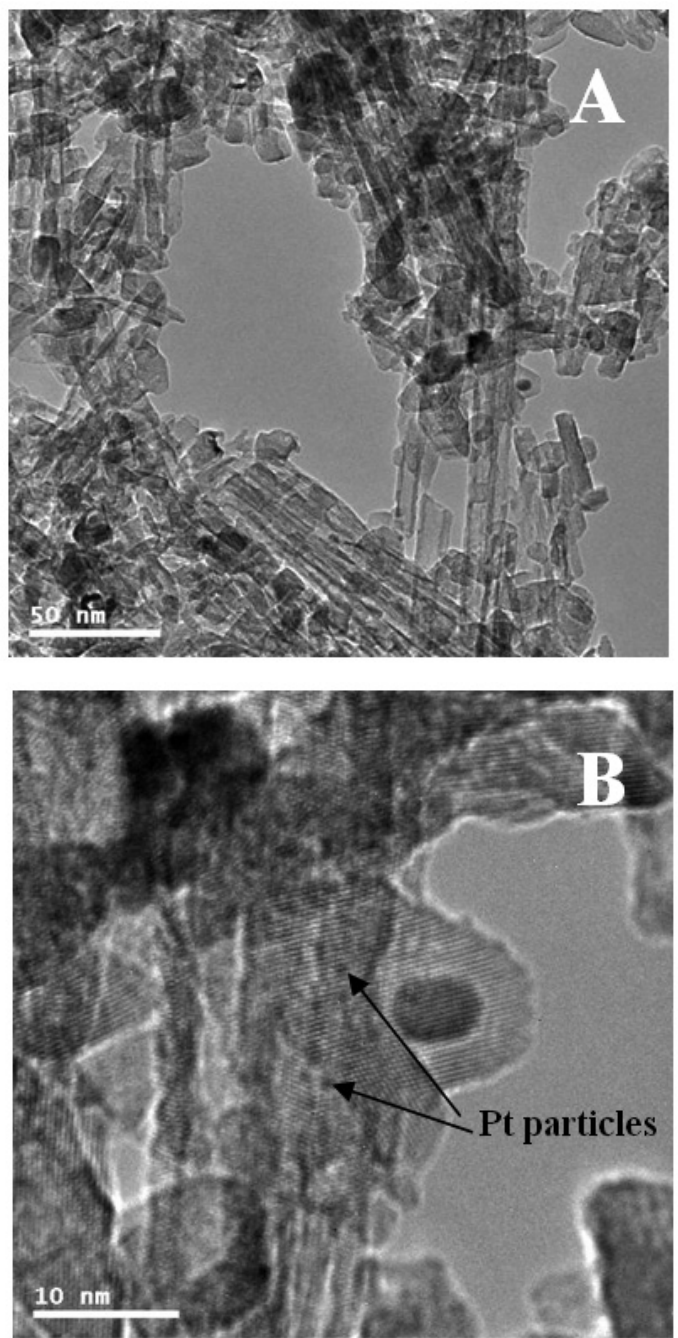

Fig. 1: TEM (A) and HR-TEM (B) images of Pt/TiO2 with 1wt.\% platinum.

From Fig. 1B, black particles with size less than $1 \mathrm{~nm}$ (marked with arrow) can be observed, which should be platinum particles come from $[\mathrm{PtCl6}]^{2-}$ ions. As soon as the $\mathrm{Pt} / \mathrm{TiO}_{2}$ forms, the photoelectrochemical cell consisting of Pt and $\mathrm{TiO}$ emerges. Reference has reported that $\mathrm{Pt} / \mathrm{TiO}$ could photocatalyzes water splitting ${ }^{[28]}$. Under the excitation of UV irradiation, the active intermediate $\mathrm{H}^{*}$ coming from water splitting on the $\mathrm{Pt} / \mathrm{TiO}_{2}$ can react with some of $\mathrm{O}$ atoms on the surface of nanotubes, which may weaken or break Ti-O bonds and mangle the tubular structure of titanate nanotubes. In other words, the formation of platinum particles and the damage of titanate nanotubes may take place at the same time. The similar results appear as the titanate nanotubes supported $\left[\mathrm{PtCl}_{6}\right]^{2-}$ ions are reduced with hydrogen gas at $200{ }^{\circ} \mathrm{C}$. Although photoreductive deposition process can result in formation of very small metal particles and prevent the formed platinum particles from agglomeration, the tubular structure of some nanotubes is destroyed badly. In order to validate the conclusions above, pure titanate nanotubes are dispersed in pure water and treated under UV light for $3 \mathrm{~h}$. Fig. 2 shows TEM images of Pt-free $\mathrm{TiO}_{2}$ titanate nanotubes treated by UV irradiation. It can be seen that the length of the treated nanotubes is more than hundreds of nanometer. Their tubular structure remains, and no obvious damage is observed. It can be concluded that the platinum particles formed in photoreductive deposition process take a part of an important action for the collapse of the titanate nanotubes. XRD analyses are carried out to further identify crystal phases of the samples.
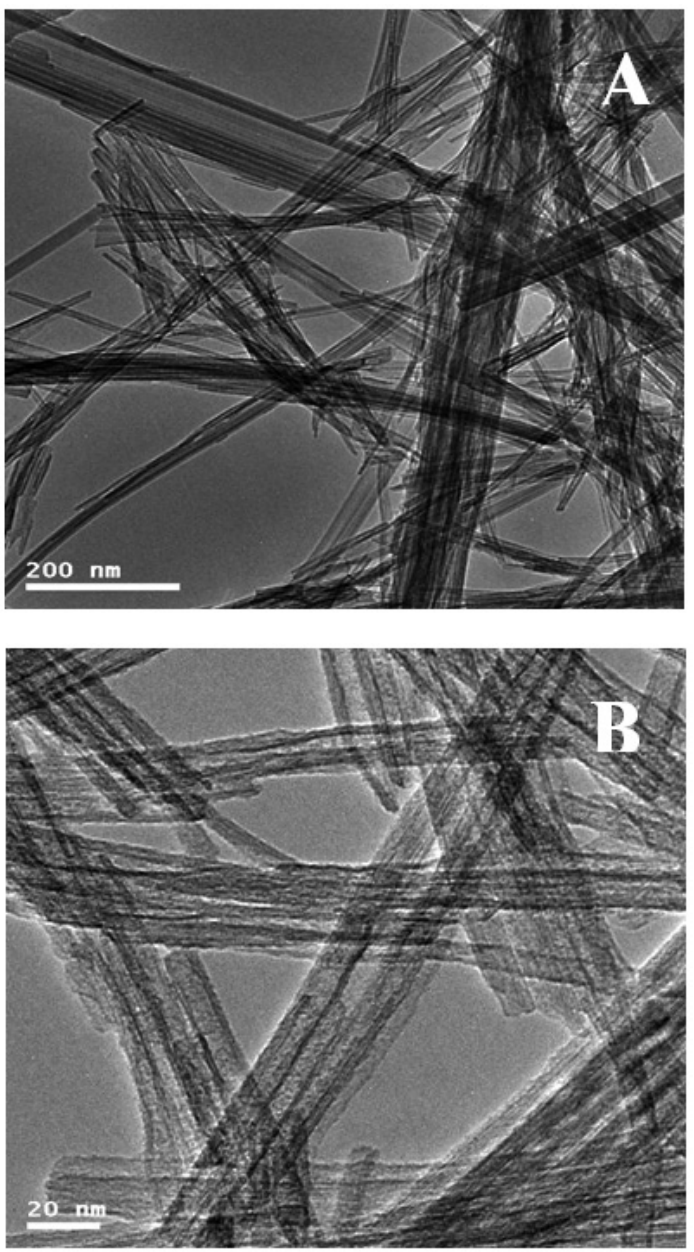

Fig. 2: TEM images of Pt-free titanate nanotubes treated using UV irradiation.

Fig. 3 depicts the XRD patterns of titanate nanotubes and $\mathrm{Pt} / \mathrm{TiO}_{2}$ with different Pt contents. It can be seen that the crystal phase of the nanotubes changes after the photoreduction process. The as-prepared nanotubes, whose diffraction peaks are relatively weak, are composed of titanate $\mathrm{H}_{2} \mathrm{Ti}_{2} \mathrm{O}_{5} \cdot \mathrm{H}_{2} \mathrm{O}$ (JCPDS 47-0124) instead of anatase $\mathrm{TiO}_{2}$ (Fig. 3a), which is confirmed by the peaks at $2 \theta=9.2^{\circ}$ and $24^{\circ}$. The two peaks correspond well to $\left(\begin{array}{lll}2 & 0 & 0\end{array}\right)$ and (1 110 ) reflections of $\mathrm{H}_{2} \mathrm{Ti}_{2} \mathrm{O}_{5} \cdot \mathrm{H}_{2} \mathrm{O}$, respectively. After platinum is loaded, the intensity of diffraction peaks at $2 \theta=9.2^{\circ}$ and $24^{\circ}$ decreases obviously, while that of the other diffraction peaks increases. When the content of platinum reaches at $1 \mathrm{wt} . \%$, the reflections of $\mathrm{H}_{2} \mathrm{Ti}_{2} \mathrm{O}_{5} \cdot \mathrm{H}_{2} \mathrm{O}$ are hardly detectable, and all peaks of anatase $\mathrm{TiO}_{2}$ (JCPDS 21-1272) appear, which means the titanate has been converted into anatase completely. It has been reported that the crystal phase influences the structure of nanotubes ${ }^{[25]}$. So the structure of nanotubes in $\mathrm{Pt} / \mathrm{TiO}_{2}$ may be partly damaged in the process of phase transformation. Furthermore, it can be observed that the peak intensity of anatase $\mathrm{TiO}_{2}$ increases with the increase of amount of platinum, which indicates that the 
titanate turns into anatase $\mathrm{TiO}_{2}$ in the irradiation process and platinum plays a key role in this transformation. It is also in accord with the results of TEM images. Surface area is an evident parameter for the tubular catalysts. The specific surface areas of hydrogen titanate nanotubes and $2 \mathrm{wt} . \% \mathrm{Pt} / \mathrm{TiO}_{2}$ are measured to be 428 and $175 \mathrm{~m}^{2} / \mathrm{g}$, respectively. It can be seen that the structure of $2 \mathrm{wt.} \% \mathrm{Pt} / \mathrm{TiO}$, should have been damaged obviously. Although the crystal phase and structure of nanotubes changes after the irradiation process, the diffraction peak of platinum is not found in the $\mathrm{Pt} / \mathrm{TiO}_{2}$ with various platinum contents. The reasonable interpretation should be that the platinum particles in them are too small to be detected by XRD.

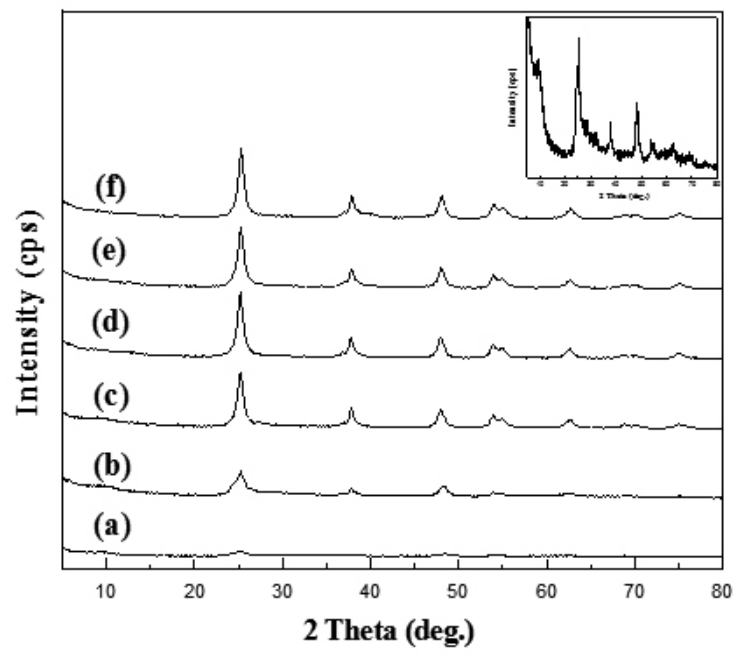

Fig. 3: XRD patterns of as-prepared titanate nanotubes (a), 0.5 wt. $\%$ (b), 1 wt.\% (c), 1.5 wt.\% (d), 2 wt. $\%$ (e) and 2.5 wt.\% (f) $\mathrm{Pt} / \mathrm{TiO} 2$ (inset curve is the enlarged XRD pattern of sample a).

In order to validate the existence of platinum in the samples, XPS spectra are used to analyze the samples. The $\mathrm{Pt} / \mathrm{Ti}$ atomic ratio of $\mathrm{Pt} / \mathrm{TiO}_{2}$ with 1 wt.\% platinum is examined to be 0.03 , and is higher than the calculated one. It indicates a certain surface platinum enrichment. The deposition process should be the reason for the above result. In this process, most of the platinum nanoparticles deposited on the surface of nanotubes and relatively high platinum content can be detected by XPS. Fig. 4 shows the high resolution XPS spectra of Ti $2 p$. The Ti $2 p_{12}$ and Ti $2 p_{32}$ spin-orbital splitting photoelectrons for the sample are located at binding energies of 464.2 and $458.4 \mathrm{eV}$, respectively, which is in agreement with the reported literature values ${ }^{[29,30]}$, showing the presence of $\mathrm{Ti}^{4+}$

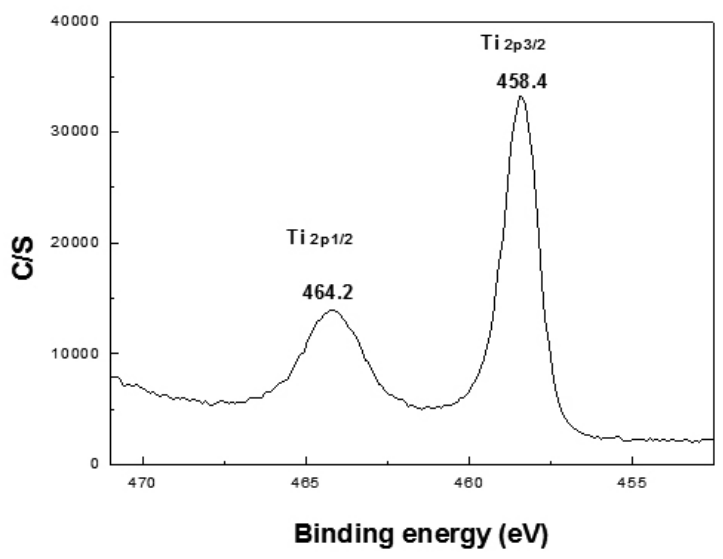

Fig.4: High resolution XPS spectra of the Ti 2p region for $1 \mathrm{wt} . \% \mathrm{Pt} / \mathrm{TiO} 2$.

Fig. 5 shows the $\mathrm{O} 1 \mathrm{~s}$ XPS spectra of $\mathrm{Pt} / \mathrm{TiO}_{2}$. The main peak of $\mathrm{O} 1 \mathrm{~s}$ located at about $529.8 \mathrm{eV}$, which has a similar energy to the $\mathrm{O} 1 \mathrm{~s}$ electron binding energy of $\mathrm{TiO}_{2}$, can be assigned to the peak of lattice oxygen in $\mathrm{TiO}_{2}$ nanotubes. The O 1s signal shows a "shoulder" located at the side of higher binding energies, indicating a great amount of surface hydroxyl groups or chemisorbed water molecules ${ }^{[29,30]}$. As indicated in the XRD patterns, there are still titanate remains in the $1 \mathrm{wt} . \% \mathrm{Pt} / \mathrm{TiO}$, catalyst after $3 \mathrm{~h}$ irradiation under UV light. As a result, large amounts of hydroxyl exist in the tubular catalyst, and "shoulder" at higher binding energies for O 1s XPS exhibits. Fig. 6 shows the high resolution XPS spectra of the $\mathrm{Pt} 4 \mathrm{f}$ region of $\mathrm{Pt} / \mathrm{TiO}_{2}$. It can be seen that the binding energies of $\mathrm{Pt} 4 \mathrm{f}_{5 / 2}$ and $\mathrm{Pt} 4 \mathrm{f}_{7 / 2}$ are 76.6 and $72.6 \mathrm{eV}$, respectively. It has been reported that the binding energies of $\mathrm{Pt} 4 \mathrm{f}_{5 / 2}$ and $\mathrm{Pt} 4 \mathrm{f}_{7 / 2}$ are 74.8 and $71.5 \mathrm{eV}$ for $\mathrm{Pt}^{0}$, while are 77.7 and $74.4 \mathrm{eV}$ for PtO. It seems that except platinum exists in the $\mathrm{Pt} / \mathrm{TiO}_{2}$, platinum oxide also exists in the samples ${ }^{[1,32]}$.

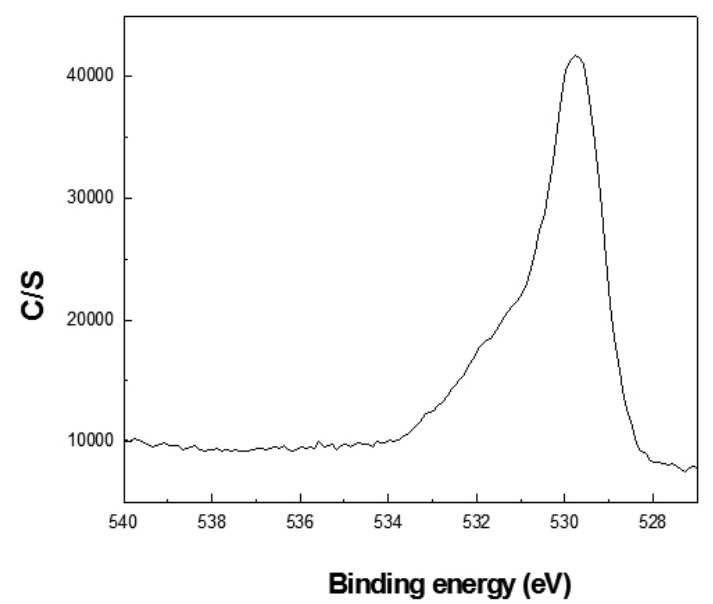

Fig.5: High resolution XPS spectra of the O 1s region for $1 \mathrm{wt} . \% \mathrm{Pt} / \mathrm{TiO} 2$.

After platinum is loaded, the color of samples shows distinct difference, and the color varies with the contents of platinum. To explore the optical absorption properties of the samples, UV-Vis diffuse reflectance spectra of the samples are measured. Fig. 7 shows the diffuse reflectance spectra of pure nanotubes and $\mathrm{Pt} / \mathrm{TiO}_{2}$ with different platinum concentrations. It can be seen that the optical absorption enhances significantly in the visible region of 400$800 \mathrm{~nm}$ after platinum is loaded, and the optical absorption increases with the contents of platinum, corresponding to the buff and grey color of the powder. The increase in absorbance should come from scattering effects from the platinum particles ${ }^{[33]}$ or from surface resonance ${ }^{[34]}$.

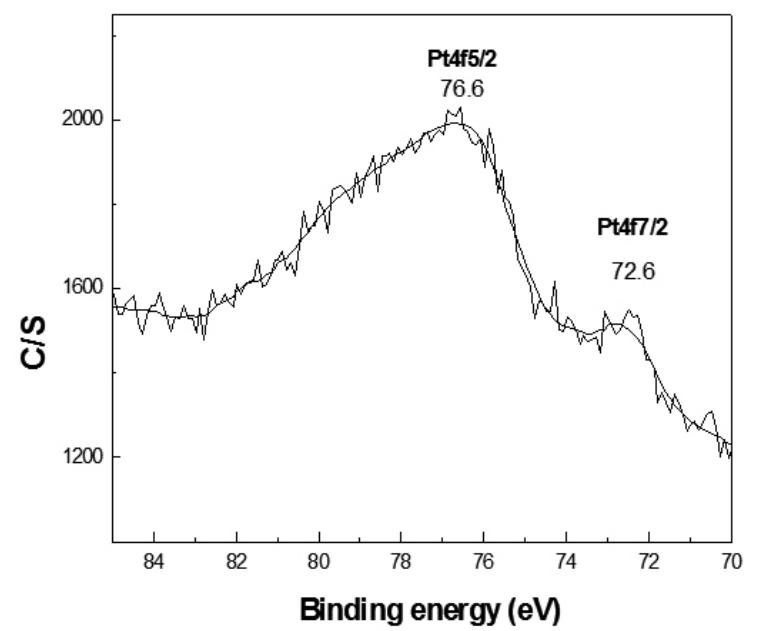

Fig.6: Higher resolution XPS spectra of the Pt $4 \mathrm{f}$ region for $1 \mathrm{wt} . \% \mathrm{Pt} /$ $\mathrm{TiO} 2$.

In order to investigate the photocatalytic performance of the prepared samples, their photocatalytic performances are evaluated by the degradation rates of methyl orange. Fig.8 shows the photocatalytic activity of $\mathrm{Pt} / \mathrm{TiO}_{2}$ as a function of Pt contents, and catalytic performances of the samples are revealed 
by the percent of residual methyl orange after different irradiation times. It is obvious that the contents of platinum in samples have great influence on the photocatalytic activity of $\mathrm{Pt} / \mathrm{TiO}_{2}$. A small amount of platinum loading $(0.5$ wt.\%) results in the increase of the photocatalytic activity of $\mathrm{TiO}_{2}$ greatly. As the contents of platinum are in the range of $0.5 \mathrm{wt} . \%$ and $1.5 \mathrm{wt.} \%$, the photocatalytic activity of sample increases with the increase of platinum content. When amount of platinum is $1.5 \mathrm{wt} \%$, the activity of sample arrives at the highest. $91 \%$ of the methyl orange is degraded after 30 min irradiation. However, a further increasing amount of platinum reduces the photocatalytic activity. When the content of platinum reaches at $2.5 \mathrm{wt} . \%$, the activity of $\mathrm{Pt} / \mathrm{TiO}_{2}$ even becomes lower than that of pure titanate nanotubes. In this photocatalytic system, $\mathrm{TiO}_{2}$ are active centers, and platinum particles act as electron acceptor, which promotes interfacial charge-transfer processes ${ }^{[2,35]}$. The photocatalytic activities of samples with various platinum contents display that the optimum content of platinum in sample is $1.5 \mathrm{wt} . \%$. As the content of platinum is $0.5 \mathrm{wt} . \%$, more electron acceptor sites (platinum particles) form and the photogenerated hole/electron pairs can be separated before recombination. The $1.5 \mathrm{wt} . \%$ loading content could be the most efficient separation of photoinduced hole/electron pairs. When the content of platinum is higher (2 wt.\% and $2.5 \mathrm{wt} . \%$ ), space between the platinum particles becomes narrow; the light can be shielded by the supported platinum particles, and the efficient surface of catalyst decreases. In this case, the platinum particles perhaps turn into new hole/electron recombination sites. As a result, excess platinum loading decrease the photocatalytic active centers on $\mathrm{TiO}_{2}$. The photocatalytic activity of P25 is also included in this figure for comparison. It can be observed that our $\mathrm{Pt} / \mathrm{TiO}_{2}$ catalysts with $1 \mathrm{wt} . \%$ and $1.5 \mathrm{wt} . \%$ platinum have higher activity under the same reaction condition. The recycle utilize of $\mathrm{Pt} / \mathrm{TiO}_{2}$ also shows good results. Due to the high sedimentation rate of the one-dimensional catalyst, $\mathrm{Pt} /$ $\mathrm{TiO}_{2}$ can be recycled and expected to be useful in practical application.

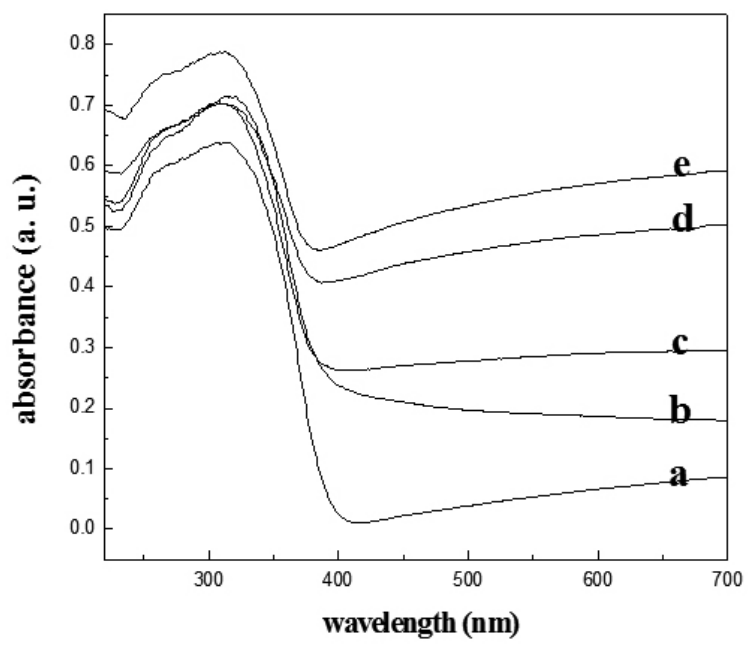

Fig.7: UV-Vis diffuse reflectance spectra of titanate nanotubes (a) and Pt/ $\mathrm{TiO} 2$ with 1 wt. $\%$ (b), 1.5 wt. $\%$ (c), 2 wt.\% (d) and 2.5 wt.\% (e) platinum.

\section{CONCLUSIONS}

Pt-modified $\mathrm{TiO}_{2}$ with one-dimensional structure can be prepared by using hydrogen titanate nanotubes as support after a photoreductive deposition process. The existence of platinum has obvious influence on the structure and catalytic performance of the hydrogen titanate nanotubes. During the fabrication process of $\mathrm{Pt} / \mathrm{TiO}_{2}$, platinum can induce the transformation of titanate to $\mathrm{TiO}_{2}$, which results in damage of the tubular structure. The photocatalytic activity of $\mathrm{Pt} / \mathrm{TiO}_{2}$ for degradation of methyl orange is also depended on the content of platinum. When the content of platinum is $1.5 \mathrm{wt} . \%$, the $\mathrm{Pt} / \mathrm{TiO}$, shows the highest photocatalytic activity.

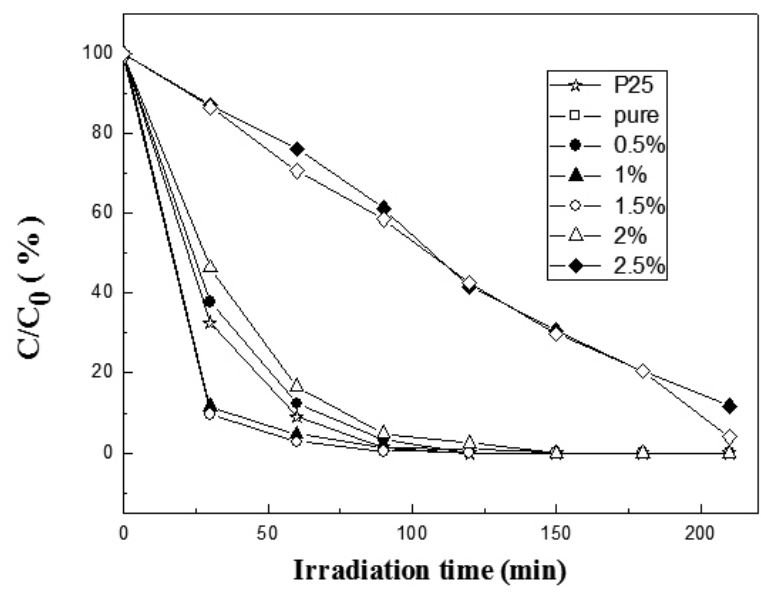

Fig.8: The photocatalytic activity of $\mathrm{P} 25$ and $\mathrm{Pt} / \mathrm{TiO} 2$ with various contents of platinum.

\section{ACKNOWLEDGMENTS}

This work was supported by the National Natural Science Foundation of China (grant number: 21071086), Asian Research Center at Nankai University, the Research Fund for the Doctoral Program of Higher Education (200800551036) and Fundamental Research Funds for the Central Universities (Nankai University 65010031).

\section{REFERENCES}

[1] S. Mozia, Catal. Today. 156, 198, (2010)

[2] S. Kaneco, Y. Chen, P. Westerhoff, Scripta. Mater. 56, 373, (2007)

[3] W. Huang, X. Tang, Y. Wang, Chem. Commun. 15, 1415, (2000)

[4] X. Zhang, F. Zhang, K. Y. Chan, Mater. Chem. Phys. 97, 384, (2006)

[5] S. Ikeda, N. Sugiyama, B. Pal, Phys. Chem. Chem .Phys. 3, 267, (2001)

[6] B.L. Zhu, K.R. Li, Y.F. Feng, Catal. Lett. 118, 55, (2007)

[7] Y. Tian, T. Tatsuma. J. Am. Chem. Soc. 127, 7632, (2005)

[8] H. Li, B.L. Zhu, Y.F. Feng, J. Solid State Chem. 180, 2136, (2007)

[9] H.Q. An, J. Zhou, J.X. Li, Catal.Commum. 11, 175, (2009)

[10] R. Asahi, T. Morikawa, T. Ohwaki, Science, 293, 269, (2001)

[11] J.A. Grasser, D.S. Muggli, Rev. Sci. Instrum. 80, 075106, (2009)

[12] D.U. Hong, C.H. Han, S.H. Park, Curr. Appl. Phys. 9, 172, (2009)

[13] Y. Shi, Z. Yang, X. Feng, Chinese J. Catal. 24,663, (2003)

[14] H.R. Kim, J .Chattopadhyay, J.I. Son, Korean J. Chem. Eng. 25, 775, (2008)

[15] U. Siemon, D. Bahnemann, J.J. Testa, J. Photoch. Photobio A. 148, 247, (2002)

[16] A. Mills, G. Porter. J. Chem. Soc., Faraday Trans. 78, 3659, (1982)

[17] X. Quan, S.G. Yang, X.L. Ruan, Environ. Sci. Technol. 39, 3770, (2005)

[18] G.K. Mor, M.A. Carvalho, O.K. Varghese, J. Mater. Res. 19, 628, (2004)

[19] G. LI, Z.Q. LIU, L. WANG, Chinese J. Inorg. Chem. 25, 1031, (2009)

[20] Y.G. Guo, J.S. Hu, H.P. Liang, Adv. Funct. Mater. 15, 196, (2005)

[21] H. Imai, Y. Takei, K.J. Shimizu, Mater. Chem. 9, 2971, (1999)

[22] T. Kasuga, M. Hiramatsu, A. Hoson, Langmuir, 14, 3160, (1998)

[23] H.H. Bao, Zh.D. Xu, H.Y. Yin, Chinese J. Inorg. Chem. 21, 374, (2005)

[24] D.V. Bavykin, F.C. Walsh, Eur. J. Inorg. Chem. 977, (2009)

[25] M. Zhang, Z.S. Jin, J.W. Zhang, J. Mol. Catal. A. 217, 203, (2004)

[26] B.L. Zhu, Q. Guo, X.L. Huang. J. Mol. Catal. A.. 249, 211, (2006)

[27] H.Q. An, B.L. Zhu, J.X. Li, J. Phys. Chem. C. 112, 18772, (2008)

[28] M. Kitano, M. Takeuchi, M. Matsuoka, Catal. Today, 120,133, (2007)

[29] H.M. Liu, W.S. Yang, Y. Ma, Langmuir, 19, 3001, (2003)

[30] K. Nagaveni, M.S. Hegde, N. Ravishankar, Langmuir, 20, 2900, (2004)

[31] A. Holmgren, F. Azarnoush, E. Fridell, Appl. Catal. B. 22, 49, (1999)

[32] S. H. wang, M.C. Lee, W. Choi, Appl. Catal. B. 46, 49, (2003)

[33] C.W. Chen, D. Tano, M. Akashi, Colloid. Polym. Sci. 277, 488, (1999)

[34] I.M. Arabatzis, T. Stergiopoulos, D. Andreeva, J. Catal. 220, 127, (2003)

[35] M. Anpo, M. Takeuchi, J. Catal. 216, 505, (2003). 